\title{
Cloning strategies for heterologous expression of the bacteriocin enterocin A by Lactobacillus sakei Lb790, Lb. plantarum NC8 and Lb. casei CECT475
}

Juan J. Jiménez¹, Dzung B. Diep², Juan Borrero', Loreto Gútiez', Sara Arbulu', Ingolf F. Nes², Carmen Herranz', Luis M. Cintas ${ }^{1}$ and Pablo E. Hernández ${ }^{1 *}$

\begin{abstract}
Background: Bacteriocins produced by lactic acid bacteria ( $L A B$ ) attract considerable interest as natural and nontoxic food preservatives and as therapeutics whereas the bacteriocin-producing $L A B$ are considered potential probiotics for food, human and veterinary applications, and in the animal production field. Within LAB the lactobacilli are increasingly used as starter cultures for food preservation and as probiotics. The lactobacilli are also natural inhabitants of the gastrointestinal (Gl) tract and attractive vectors for delivery of therapeutic peptides and proteins, and for production of bioactive peptides. Research efforts for production of bacteriocins in heterologous hosts should be performed if the use of bacteriocins and the LAB bacteriocin-producers is ever to meet the high expectations deposited in these antimicrobial peptides. The recombinant production and functional expression of bacteriocins by lactobacilli would have an additive effect on their probiotic functionality.

Results: The heterologous production of the bacteriocin enterocin A (EntA) was evaluated in different Lactobacillus spp. after fusion of the versatile Sec-dependent signal peptide $\left(\mathrm{SP}_{\text {usp } 45}\right)$ to mature EntA plus the EntA immunity gene (entA + entiA) (fragment UAI), and their cloning into plasmid vectors that permitted their inducible (pSIP409 and pSIP411) or constitutive (pMG36c) production. The amount, antimicrobial activity (AA) and specific antimicrobial activity (SAA) of the EntA produced by Lactobacillus sakei Lb790, Lb. plantarum NC8 and Lb. casei CECT475 transformed with the recombinant plasmids pSIP409UAI, pSIP411UAI and pMGUAI varied depending of the expression vector and the host strain. The $L b$. casei CECT475 recombinant strains produced the largest amounts of EntA, with the highest AA and SAA. Supernatants from $\mathrm{Lb}$. casei CECT (pSIP411UAI) showed a 4.9-fold higher production of EntA with a 22.8-fold higher AA and 4.7-fold higher SAA than those from Enterococcus faecium T136, the natural producer of EntA. Moreover, supernatants from Lb. casei CECT475 (pSIP411UAl) showed a 15.7- to 59.2-fold higher AA against Listeria spp. than those from E. faecium T136.
\end{abstract}

Conclusion: $L$ b. casei CECT457 (pSIP411UAI) may be considered a promising recombinant host and cell factory for the production and functional expression of the antilisterial bacteriocin EntA.

Keywords: Bacteriocins, Enterocin A, Lactic acid bacteria (LAB), Expression systems, Lactobacillus spp., Heterologous bacteriocin production

\footnotetext{
${ }^{*}$ Correspondence: ehernan@vet.ucm.es

1 Departamento de Nutrición, Bromatología y Tecnología de los

Alimentos, Facultad de Veterinaria, Universidad Complutense de Madrid

(UCM), Avenida Puerta de Hierro, s/n, 28040 Madrid, Spain

Full list of author information is available at the end of the article
} 


\section{Background}

Within lactic acid bacteria (LAB) the lactobacilli are increasingly used as starter cultures for food preservation and as probiotics [1]. The lactobacilli are also natural inhabitants of the gastrointestinal (GI) tract and attractive vectors for delivery of therapeutic peptides and proteins and production of bioactive peptides [2,3]. Furthermore, most probiotics enhance intestinal barrier function, display immunomodulatory activity and exert protective effects against pathogens due to the production of antimicrobial compounds [4-6]. Since the in situ production of the antilisterial bacteriocin Abp118 is the major reason of the well-documented probiotic effect of Lb. salivarius UCC118 against Listeria monocytogenes EFDe infections in mice [7,8], the production of bacteriocins by lactobacilli surely would have an additive effect on their probiotic functionality.

Bacteriocins are ribosomally synthesized antimicrobial peptides secreted by bacteria, and those produced by LAB attract considerable interest as natural and nontoxic food preservatives, for human and veterinary applications, and in the animal production field $[9,10]$. Most bacteriocins, including those produced by enterococci and named enterocins are synthesized as biologically inactive precursors or prepeptides containing an $\mathrm{N}$-terminal extension of the so-called double-glycine type (leader sequence) that is cleaved concomitantly with export across the cytoplasmic membrane by dedicated ATP-binding cassette transporters (ABC transporters) and their accessory proteins [11]. However, many secreted prokaryotic proteins and a few bacteriocins contain N-terminal extensions of the Sec-dependent type (signal peptide) that are proteolytically cleaved concomitantly with peptide externalization by the general secretory pathway (GSP) or Sec-dependent pathway [12]. And the signal peptide (SP) of secretory proteins and bacteriocins may drive fused mature bacteriocins to SPs for their secretion by recombinant $\operatorname{LAB}[9,10,13]$. The mature bacteriocins are often cationic, amphiphilic molecules of 20-60 amino acid residues that are classified into two main classes: the lantibiotics or class I that consist of modified bacteriocins and the class II or nonmodified bacteriocins which are further subdivided in class IIa, class IIb, class IIc, and class IId. Among these subgroups, the class IIa bacteriocins (also referred to as pediocin-like bacteriocins) have attracted much attention due to their strong antilisterial activity [14]. Additional subgroups have been suggested for leaderless peptides, circular bacteriocins, linear peptides derived from large proteins, and the glycosylated bacteriocins [15].

Accordingly, bacteriocins with high antimicrobial activity against bacterial pathogens could be overproduced and would contribute to the probiotic effect of recombinant Lactobacillus spp. strains $[8,16]$. Enterocin A (EntA) is a class IIa bacteriocin whose synthesis is directed by the entAIFKRTD operon and from which entA encodes the enterocin A prepetide synthesized as an 18 amino acid leader sequence of the double-glycine type and the 47 amino acid mature bacteriocin [17, 18]. Moreover, its potent antilisterial activity has driven interest for its overproduction by LAB mostly of the genera Lactococcus, Enterococcus and Pediococcus $[13,19]$ and also by yeasts from the genera Pichia, Kluyveromyces, Hansenula and Arxula, throughout fusions of mature EntA to signal peptides (SPs) that act as secretion signals [20, 21]. Accordingly, of biotechnological interest would be the design and construction of recombinant Lactobacillus spp. for the controlled or constitutive heterologous production of bacteriocins with high antimicrobial activity against Listeria spp.

In this work, Lb. sakei Lb790 a non-bacteriocin producing strain from meat origin [22], Lb. plantarum NC8 from grass silage encoding the two-peptide plantaricins PlnEF, PlnJK and PLNC $8 \alpha \beta$ of narrow inhibitory spectra $[23,24]$ and $L b$. casei CECT475, a reported non-bacteriocin producer from dairy origin, were transformed with derivatives of the inducible protein expression vectors PSIP409 and pSIP411 and the constitutive pMG36c expression vector, for evaluation of the production of EntA and its functional expression as determined by evaluation of their antimicrobial activity against Listeria spp.

\section{Results}

\section{Heterologous production and functional expression of EntA by different Lactobacillus spp. strains}

Since the leader sequence of EntA $\left(\mathrm{LS}_{\text {entA }}\right)$ is of a doubleglycine type which restricts expression of the bacteriocin to limited LAB strains containing homologous dedicated $A B C$-transporters, we therefore employed the more versatile signal peptide $\mathrm{SP}_{u s p 45}$ for the Sec-dependent externalization of mature EntA, as well as the use of protein expression vectors that permitted the inducible (pSIP409, pSIP411) or constitutive (pMG36c) production of the synthesized bacteriocin by different Lactobacillus spp. host strains. Thus, cloning of the lactococcal $\mathrm{SP}_{u s p} 45$ fused to mature entA (EntA) and entiA (EntI) (fragment UAI) into plasmids pSIP409, pSIP411 and pMG36c resulted in the plasmid derived vectors pSIP409UAI, pSIP411UAI and pMGUAI, respectively. Transformation of $L b$. sakei Lb790, Lb. plantarum $\mathrm{NC} 8$ and Lb. casei CECT475 with plasmids pSIP409UAI, pSIP411UAI and pMGUAI yielded recombinant Lactobacillus spp.-derived strains which were further checked by bacteriocinogenicity tests, PCR and sequencing of the inserts. Halos of inhibition of variable sizes were observed by all transformed Lactobacillus spp. (results not shown), confirming that recombinant plasmids were responsible of their antimicrobial activity. 
The production and functional expression of the EntA in supernatants of the recombinant Lactobacillus spp. strains was quantified using specific anti-EntA antibodies in a NCI-ELISA, and by a microtitre plate assay (MPA). None of the native Lactobacillus spp. strains showed production of EntA (Table 1). The production of EntA by Lb. sakei Lb790 (pSIP411UAI) and Lb. casei CECT475 (pSIP411UAI) was 2.7- and 4.9-fold higher, respectively, whereas production of EntA by $L b$. plantarum NC8 (pSIP411UAI) was 4.7-times lower than production of EntA by the natural producer E. faecium T136. The production of EntA by Lb. sakei Lb790, Lb. plantarum NC8 and $L b$. casei CECT475 transformed with either pSIP409UAI or pMGUAI, was 1.1- to 6.3-times lower than production of EntA by E. faecium T136 (Table 1).

When supernatants of the recombinant $L b$. sakei Lb790, Lb. plantarum NC8 and Lb. casei CECT475 strains were evaluated for their antimicrobial activity against E. faecium P13 $\left(\right.$ EntA $\left.^{\mathrm{S}}\right)$, the antimicrobial activity (AA) of Lb. sakei Lb790 (pSIP411UAI) was 2.2-fold higher while its specific antimicrobial activity (SAA) was 1.2-times lower than the EntA produced by E. faecium T136 (Table 1). Lb. sakei Lb790 (pSIP409UAI) showed 2.2-times lower AA and 1.5-times lower SAA and $L b$. sakei Lb790 (pMGUAI) showed 15-times lower AA and 5.5-times lower SAA, when compared to the control EntA producer. All $\mathrm{Lb}$. plantarum NC8 recombinants showed a 17.1- to 38-times lower AA and 3.6- to 6.0times lower SAA, when compared to the control EntA producer. However, transformation of $L b$. casei CECT475 with plasmids pSIP409UAI, pSIP411UAI and pMGUAI generated supernatants with 1.3-, 22.8- and 1.2-fold higher AAA and 4.3-, 4.7- and 2.1-fold higher SAA, respectively, than those from E. faecium T136 (Table 1).

Furthermore, the evaluation of the antimicrobial activity of supernatants from the recombinant Lb. sakei Lb790, Lb. plantarum NC8 and Lb. casei CECT475 against five Listeria spp. and six L. monocytogenes strains, showed that supernatants from Lb. sakei Lb790 (pSIP411UAI) displayed 3.8-times lower to 2.7-fold higher AA whereas those from $L b$. sakei Lb790 (pSIP409UAI) and Lb. sakei Lb790 (pMGUAI) showed 1.8- to 9.1-times lower and a 6.0- to 45-times lower AA, respectively, than those from E. faecium T136. Supernatants from all recombinant $L b$. plantarum NC8 strains showed a 4.9- to 120-times much lower AA than the control EntA producer (Table 2). However, despite the measurable and non-previously reported antimicrobial activity of $L b$. casei CECT475, the supernatants from $L b$. casei CECT475 (pSIP409UAI) showed 1.6- to 13.9-fold higher AA, those from $L b$.

Table 1 Bacteriocin production and antimicrobial activity of supernatants from recombinant strains

\begin{tabular}{|c|c|c|c|}
\hline Strain & 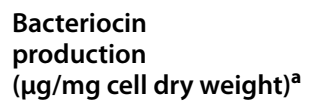 & $\begin{array}{l}\text { Antimicrobial } \\
\text { activity } \\
\text { (BU/mg cell dry weight) }\end{array}$ & $\begin{array}{l}\text { Specific antimicrobial } \\
\text { activity } \\
(\mathrm{BU} / \mu \mathrm{g} \text { Ent } A)^{\mathrm{c}}\end{array}$ \\
\hline \multicolumn{4}{|l|}{ Lactobacillus sakei } \\
\hline Lb790 & NP & NA & $\mathrm{NE}$ \\
\hline Lb790 (pSIP409UAI) & 1.3 & 324 & 249 \\
\hline Lb790 (pSIP411UAI) & 5.2 & 1578 & 303 \\
\hline Lb790 (pMGUAI) & 0.7 & 48 & 68 \\
\hline \multicolumn{4}{|l|}{ Lactobacillus plantarum } \\
\hline NC8 & NP & NA & $\mathrm{NE}$ \\
\hline NC8 (pSIP409UAI) & 0.4 & 42 & 105 \\
\hline NC8 (pSIP411 1UAI) & 0.4 & 36 & 90 \\
\hline NC8 (pMGUAI) & 0.3 & 19 & 63 \\
\hline \multicolumn{4}{|l|}{ Lactobacillus casei } \\
\hline CECT475 & NP & 102 & $\mathrm{NE}$ \\
\hline CECT475 (pSIP409UAI) & 1.7 & 958 & 1629 \\
\hline CECT475 (pSIP411UAI) & 9.3 & 16,466 & 1771 \\
\hline CECT475 (pMGUAl) & 1.1 & 869 & 790 \\
\hline \multicolumn{4}{|l|}{ Enterococcus faecium } \\
\hline $\mathrm{T} 136^{\mathrm{d}}$ & 1.9 & 721 & 379 \\
\hline
\end{tabular}

Most of the data are mean from two independent determinations in triplicate

$N P$ no production, NA no activity, NE not evaluable

a Production of EntA was calculated by using a NCI-ELISA with polyclonal antibodies specific for EntA

b Antimicrobial activity was calculated against E. faecium P13 $\left(E n t A^{s}\right)$. BU, bacteriocin units

c Specific antimicrobial activity refers to the antimicrobial activity against E. faecium $\mathrm{P} 13$ divided by the EntA produced

d Culture of E. faecium T136 used as control for production and antimicrobial activity of EntA 


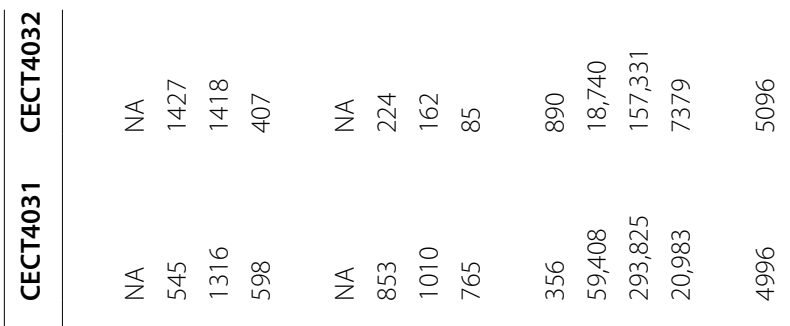

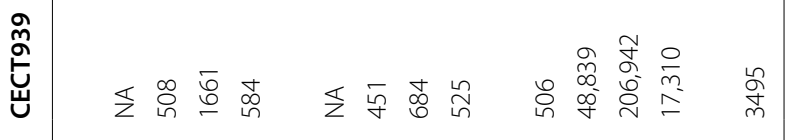

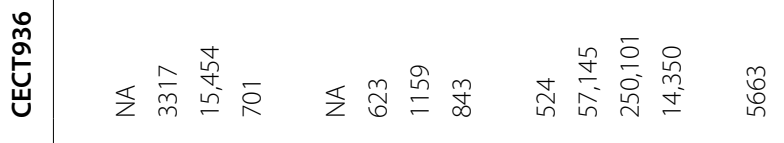

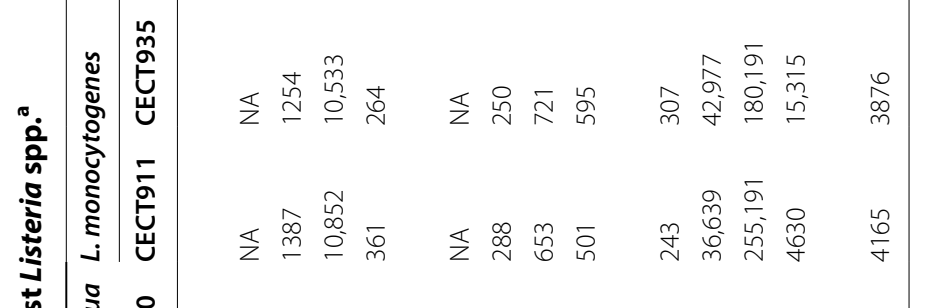

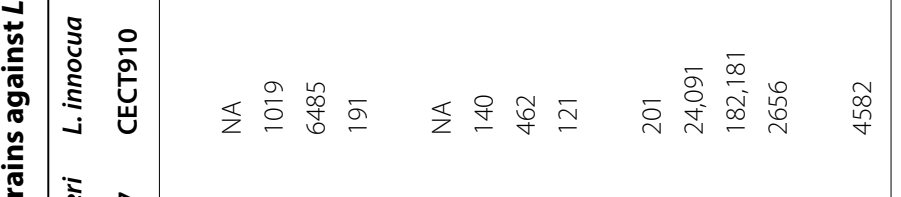

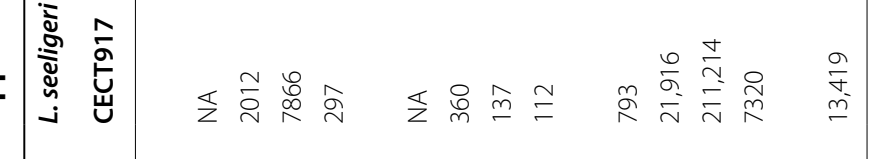

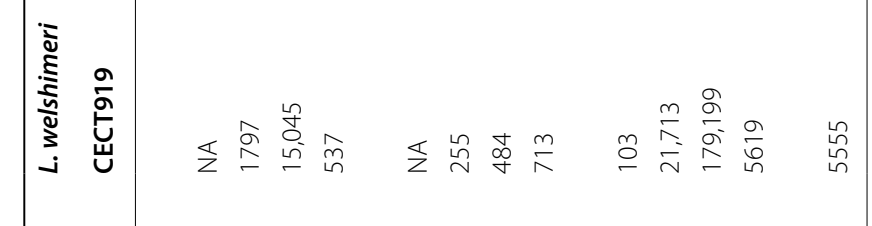

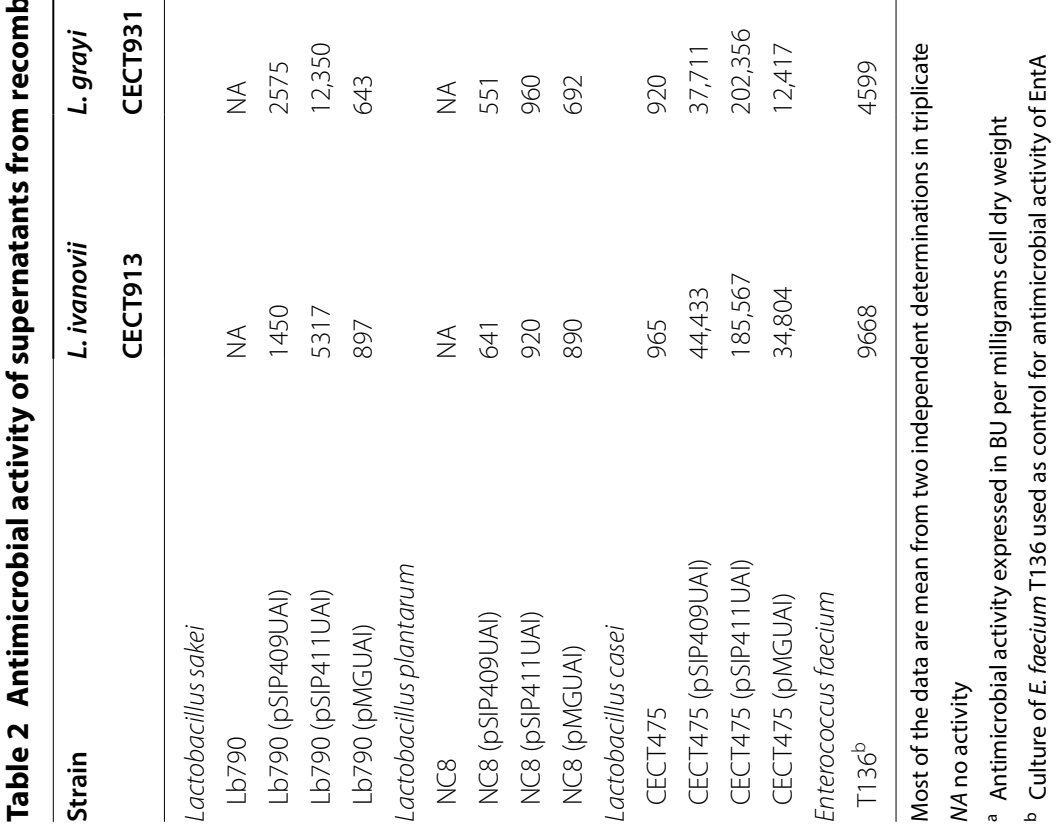


casei CECT475 (pSIP411UAI) showed 15.7- to 59.2-fold higher AA and those from $L b$. casei CECT475 (pMGUAI) showed 0.54- to 4.9-fold higher AA than those from $E$. faecium T136 (Table 2).

\section{Purification of EntA and mass spectrometry analysis}

The EntA produced by $L b$. sakei Lb790 (pSIP411UAI) and $L b$. casei CECT475 (pSIP409UAI) was purified to homogeneity following a previously described chromatographic procedure (results not shown). MALDI-TOF MS analysis of the purified EntA from Lb. sakei Lb790 (pSIP411UAI) showed a major peptide fragment of a molecular mass of $4842.62 \mathrm{Da}$ (Fig. 1a), nearly identical to the EntA produced by different recombinant yeasts [20] while the purified EntA produced by $L b$. casei CECT475 (pSIP411UAI) showed peptide fragments of different molecular massess among which a peptide fragment of $4844.53 \mathrm{Da}$, nearly identical to the observed molecular mass (4844.40 Da) of the EntA produced by $E$. faecium T136 [13], was also observed (Fig. 1b). In both purifications the peptide fragment of 4860.2 Da may correspond to oxidation $(+16 \mathrm{Da})$ of the methionine residue $\left(\mathrm{Met}^{33}\right.$ ) of the EntA to methionine sulfoxide (MetSO) (Fig. 1). The visualization by MALDI-TOF MS of peptide
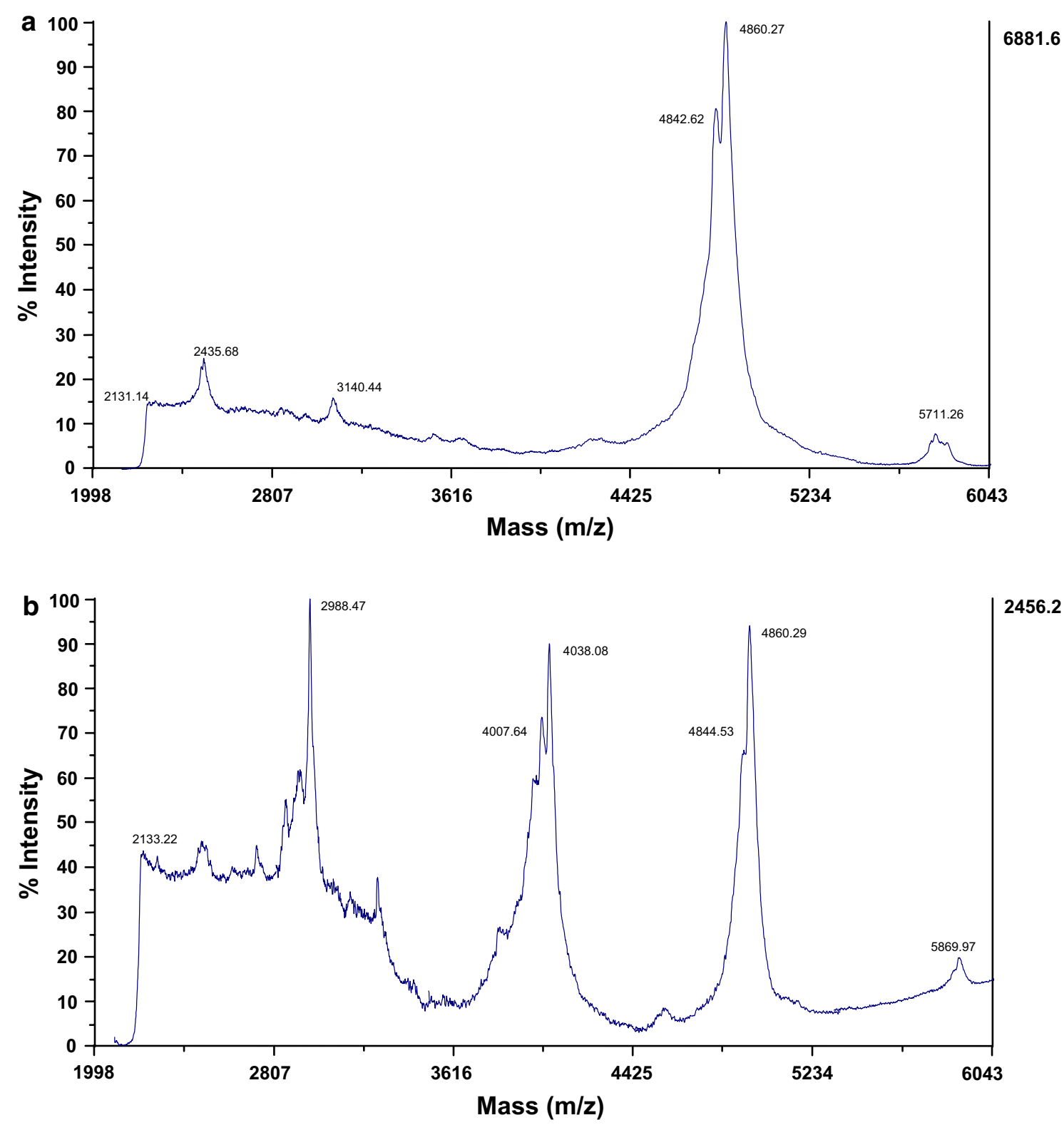

Fig. 1 Mass spectrometry analysis of purified enterocin A from Lb. sakei Lb790 (pSIP411UAI) (a), and Lb. casei CECT475 (pSIP411UAI) (b) 
fragments of different molecular massess (Fig. 1b) may suggest that the EntA produced by $L b$. casei CECT475 (pSIP411UAI) has not been purified to homogeneity or that these peptides could be responsible of the low antimicrobial activity observed in supernatants of $L b$. casei CECT475. However, treatment of crude supernatants of the control strain $L b$. casei CECT474 with proteinase $\mathrm{K}$ $(1 \mathrm{mg} / \mathrm{ml})$ revealed that the antimicrobial activity of the supernatants was not of proteinaceous nature (results not shown).

\section{Discussion}

Lactobacilli are common colonisers of the human gastrointestinal and urogenital tracts, skin and the oral cavity and they merit recognition as starters in the production of fermented products, and as probiotics $[25,26]$. They are also being evaluated for production of functional foods enriched in bioactive peptides [3]. Furthermore, production of bacteriocins by lactobacilli could find their use as natural antimicrobial peptides while the bacteriocin-producing lactobacilli could be evaluated for their improved functionality as probiotics. Several gene expression systems have been developed for efficient overproduction of heterologous proteins in LAB $[1,27,28]$. Previous studies have evaluated the production, secretion and functional expression of the EntA by different LAB, mostly of the genera Lactococcus, Enterococcus, and Pediococcus [13, 19, 29] and yeasts $[20,21]$. However, of great biotechnological interest would be the construction of recombinant Lactobacillus spp. for production of bacteriocins with known and potent antimicrobial activity against Listeria spp.

For protein expression by $L b$. sakei and Lb. plantarum but also for other Lactobacillus spp., the so-called pSIP expression vectors permits expression of the gene of interest under control of an inducible promoter by an externally added peptide pheromone [1, 28]. The pSIP system has been successfully applied for intracellular expression, secretion and surface anchoring of a variety of proteins in Lb. plantarum and Lb. sakei [1]. However, although these pSIP vectors have been evaluated for expression of different reporter proteins, they have not been yet fully evaluated for secretion and functional expression of bacteriocins. In these vectors the expression of genes of interest is driven by strong, regulated promoters derived from the bacteriocin sakacin $\mathrm{P}$ structural gene $\left(\mathrm{P}_{\text {sppA }}\right)$ or the sakacin $\mathrm{Q}$ structural gene $\left(\mathrm{P}_{\text {spp } \mathrm{Q}}\right.$ also recorded as $\mathrm{P}_{\text {orf } \mathrm{X}}$ ) with an engineered NcoI site for translational fusion cloning, as well as for components of the cognate two-component signal transduction system (SppK and SppR) which responds to an externally added peptide pheromone (SppIP). These vectors also carries a multicloning site (MCS) and the replicon derived from the narrow-host-range Lactobacillus replicon from plasmid p256 (pSIP409) or the broad-host-range, high-copynumber replicon from plasmid pSH71 (pSIP411) [28]. The expression vector pMG36c contains the low copy replication origin of plasmid pWV01 and the strong $\mathrm{P}_{32}$ promoter to drive the constitutive transcription of inserted genes into the multicloning site (MCS) of pUC18 [30]. Different homologous and heterologous signal peptides (SPs) have been also evaluated for secretion of heterologous proteins and bacteriocins by $\mathrm{LAB}$, although expression yield and secretion efficiency are not only steered by the SP but also the host producer $[1,10,13]$.

In this work, Lb. sakei Lb790, Lb. plantarum NC8 and Lb. casei CECT 475 were transformed with the recombinant plasmids pSIP409UAI, pSIP411UAI and pMGUAI for heterologous production of EntA and evaluation of its functional expression against Listeria spp. The results obtained suggest that production, secretion and antimicrobial activity of the EntA produced depend on the expression vector and the host strain (Table 1). EntA producers are protected from the antagonistic effect of this bacteriocin by the concomitant expression of a cognate immunity protein (EntiA) and bacteriocins of the class IIa, such as the EntA use components of the mannose phosphotransferase system (Man-PTS) of the susceptible cells as the target/receptor. The immunity proteins form a strong complex with the receptor proteins, thereby preventing cells from being killed $[15,31]$. Of interest is the 2.7- and 4.9-fold enhanced production of EntA by $L b$. sakei Lb790 (pSIP411UAI) and Lb. casei CECT475 (pSIP411UAI), respectively, as compared to the rest of recombinant Lactobacillus spp. and E. faecium T136 (Table 1). The production of EntA would depend, among other factors, on plasmid stability and copy number differences between pSIP409, pSIP411 and pMG36c but, more likely, might be caused by promoters used to drive gene expression. For optimization of protein production inducible systems are often considered superior to constitutive systems since the short induction time for bacteriocin production from the pSIP-inducible vectors most probably prevents EntA from attaching to cell walls, forming aggregates, and/or undergoing protease degradation [32]. The high-copy number replicon of pSIP411 may be also a contributing factor to the higher production of EntA by Lactobacillus spp. recombinants transformed with pSIP411UAI instead of pSIP409UAI.

Protein secretion is a preferred means of protein expression in the development of $\mathrm{LAB}$ as cell factories for production of biologically active compounds [33]. However, it may happen that $\mathrm{SP}_{u s p 45}$ could modulate differently the secretion of EntA by the recombinant $L b$. sakei Lb790, Lb. plantarum NC8 and Lb. casei CECT47 
hosts, as it appeared with secretion of EntA and other bacteriocins by different $\mathrm{LAB}[10,13]$. It may also happen that mature EntA remain $\mathrm{N}$-terminally associated to the cell membrane of the producer cells via a Sec-type signal peptide that is not cleaved off during secretion [34]. The different molecular folding of EntA inside the less EntA-producing recombinant $L b$. plantarum hosts may also maintain the prepeptide in an secretion-incompetent conformation [35]. It is known that Lb. plantarum $\mathrm{NC} 8$ encodes three two-peptide plantaricins of narrow inhibitory spectra, regulated by a quorum sensing based network, but unable to produce bacteriocins as pure cultures in liquid media [24]. Thus, variations in bacteriocin secretion capacities may be also governed by autoinducer peptide production and recognition and post-transcriptional factors such as codon usage, mRNA stability and translational efficiency that may steer EntA production from the recombinant $L b$. sakei Lb790 and Lb. plantarum NC8 [36]. New variants of the modular pSIP-vectors, encoding different SPs, have been tested for inducible gene expression and reporter protein secretion in Lactobacillus spp. All recombinant strains secreted the target protein nuclease A (NucA), albeit with different production levels [1].

In this work, polyclonal antibodies of predetermined specificity for EntA and an NCI-ELISA have permitted evaluation of the specific antimicrobial activity (SAA) of the produced EntA against E. faecium $\mathrm{P} 13\left(\right.$ EntA $^{\mathrm{S}}$ ). From the $L b$. sakei Lb790-derived recombinants, only $L b$. sakei Lb790 (pSIP411UAI) showed a 2.2-fold higher antimicrobial activity (AA) but a 1.2-times lower SAA than the EntA produced by E. faecium T136 (Table 1). All $L b$. plantarum NC8 recombinants showed a much lower AA and SAA when compared to the control EntA producer. However, all $L b$. casei CECT475-derived recombinants generated supernatants with higher AA and SAA than those from E. faecium T136. Of interest is the 22.8-fold higher AA and the 4.7-fold higher SAA of supernatants of Lb. casei CECT475 (pSIP411UAI) (Table 1). According to these results, it is important to consider that not always a higher bacteriocin production by recombinant LAB may report a higher AA and SAA $[9,10]$. The low $\mathrm{AA}$ and SAA of the EntA produced by the $L b$. sakei Lb790- and $L b$. plantarum NC8-hosts may depend on many factors which are difficult to determine. It is possible that: (1) regulatory responses to secretion stress activate quality control networks of the producer cells involving folding factors and housekeeping proteases [37], (2) differences in the Sec-dependent translocation and Sec-machinery, differences in protein folding, and conformational modifications of bacteriocins to a less extracellular active form may also decrease the antagonistic activity of the secreted EntA [38], (3) secretion of truncated bacteriocins may also lower the antimicrobial activity of the producer cells [10], (4) the formation of disulfide bonds (DSB) from the four cysteine residues in EntA may also play a role in the folding, structural integrity, and antimicrobial activity of the produced bacteriocin [39], and (5) the EntA contains a methionine residue that may change to an apparently less active form due to its oxidation to methionine sulfoxide [40]. The lower AA and SAA of the produced EntA may be also adscribed to differences in protein folding efficiency and bacteriocin self-aggregation [13]. Although Lb. sakei and $L b$. plantarum have been considered appropriate hosts for the recombinant production of a number of reporter proteins and enzymes [1, 41-43], the results of this work resolve $L b$. casei CECT475 as the preferred host for heterologous production and functional expression of the bacteriocin EntA.

Supernatants from all recombinant $L$ b. casei CECT475 hosts, producers of EntA, showed up to a 59.2-fold higher AA against Listeria spp. than any other Lb. sakei Lb790or Lb. plantarum NC8-recombinant producer of EntA (Table 2). Furthermore, $L b$ casei CECT (pSIP411UAI) an inducible overproducer of EntA with higher AA and SAA in its supernatants than those from E. faecium T136, could be considered as a cellular factory and an alternative to E. faecium T136 for production and recovery of the highly active antilisterial bacteriocin EntA. The controlled production of EntA by Lb. casei CECT475 (pSIP411UAI) and the constitutive production of this bacteriocin by $L b$. casei CECT475 (pMGUAI) could be also evaluated as a contributing antilisterial effect of $L b$. casei CECT475, also cited as Lb. casei ATCC393, during further evaluation of the potential of the $L b$. casei CECT475-derived recombinant strains during production of dry-fermented sausages [44, 45], production of antithrombotic and angiotensin converting enzyme (ACE)-inhibitory peptides (ACEIP) from bovine casein [46] or during production of antioxidant and antimutagenic peptides from yogurt [3].

\section{Conclusions}

The use of Lb. casei CECT475-derived strains, generally recognized as safe (GRAS) and with a qualified presumption of safety (QPS), as recombinant bacteriocin producers may provide means by which the potential benefits of antimicrobial compounds can be exploited in the food industry, human and veterinary applications, and in the animal production field. The combined use of the inducible protein expression vector pSIP411 and $L b$. casei CECT475 as the producer host, would also merit recognition as a novel gene expression system for the efficient overproduction and functional expression of EntA by $L b$. casei. 


\section{Methods}

Microbial strains, plasmids, and growth conditions

The microbial strains and plasmids used in this study are listed in Table 3. Enterococcus faecium T136 was used as the source of entA (EntA) and entiA (EntI), whereas Lactococcus lactis MG1363 was the source of the signal peptide from protein Usp45 $\left(\mathrm{SP}_{\text {usp } 45}\right)$. The lactococcal strains were propagated at $32{ }^{\circ} \mathrm{C}$ in M17 broth (Oxoid Ltd., Basingstoke, UK) supplemented with $0.5 \%(\mathrm{w} / \mathrm{v})$ glucose (GM17). The enterococcal strains and the lactobacilli were grown in MRS broth (Oxoid) at $32{ }^{\circ} \mathrm{C}$. Escherichia coli XL10 Gold (Stratagene, La Jolla, CA, USA) was grown in BHI (Oxoid) broth at $37{ }^{\circ} \mathrm{C}$ with shaking. Listeria spp. strains were cultured in BHI broth (Oxoid) at $32{ }^{\circ} \mathrm{C}$. Agar plates were made by addition of $1.5 \%(\mathrm{w} / \mathrm{v})$ agar (Oxoid) to the liquid media. When necessary, chloramphenicol (Sigma-Aldrich Inc., St. Louis, MO, USA) was added at $10 \mu \mathrm{g} \mathrm{ml}^{-1}$ for E. coli, lactococci and lactobacilli. Erythromicin (Sigma) was added at $350 \mu \mathrm{g} \mathrm{ml}^{-1}$ for E. coli and at $10 \mu \mathrm{g} \mathrm{ml}^{-1}$ for lactococci and lactobacilli. Cell dry weights of late exponential phase cultures expressed as cell dry mass were determined gravimetrically.

\section{Basic genetic techniques and enzymes}

Total genomic DNA from L. lactis MG1363 and E. faecium T136 was isolated using the Wizard ${ }^{\circledR}$ DNA Purification Kit (Promega, Madison, WI, USA). Plasmid DNA isolation was carried out using the QIAprep Spin Miniprep Kit (QIAGEN, Hilden, Germany), as suggested by the manufacturer, but cells were suspended with lysozyme $\left(40 \mathrm{mg} \mathrm{ml}^{-1}\right)$ and mutanolysin $\left(500 \mathrm{U} \mathrm{ml}^{-1}\right)$ and incubated at $37^{\circ} \mathrm{C}$ for $10 \mathrm{~min}$ before following the kit instructions. DNA restriction enzymes were supplied by New England Biolabs (Beverly, MA, USA). Ligation reactions were performed with the T4 DNA ligase (Roche Molecular

Table 3 Bacterial strains and plasmids used in this study

\begin{tabular}{|c|c|c|}
\hline Strain or plasmid & Description $^{a}$ & $\begin{array}{l}\text { Source and/or } \\
\text { reference }^{b}\end{array}$ \\
\hline \multicolumn{3}{|l|}{ Strains } \\
\hline Lactobacillus sakei Lb790 & Host strain, meat isolate, non-bacteriocin producer & {$[22]$} \\
\hline Lactobacillus plantarum NC8 & Host strain, silage isolate, plasmid free & {$[48]$} \\
\hline Lactobacillus casei CECT475 & Host strain, cheese isolate, also recorded as strain ATCC393 & CECT \\
\hline Lactococcus lactis MG1363 & Source of SP ${ }_{\text {usp 45, }}$, plasmid-free and prophage-cured derivative of L. lactis NCDO 712 & {$[51]$} \\
\hline Enterococcus faecium T136 & Enterocin A and B producer, source of entA and entiA, control strain & DNBTA [52] \\
\hline Enterococcus faecium P13 & Enterocin P producer, control strain MPA and ADT indicator & DNBTA [52] \\
\hline Listeria ivanovii CECT913 & Indicator strain, sheep isolate & CECT \\
\hline Listeria grayi CECT931 & Indicator strain, chinchilla faeces & CECT \\
\hline Listeria welshimeri CECT919 & Indicator strain, decaying vegetation & CECT \\
\hline Listeria seeligeri CECT917 & Indicator strain, soil isolate & CECT \\
\hline Listeria innocua CECT910 & Indicator strain, cow brain isolate & CECT \\
\hline Listeria monocytogenes CECT911 & Indicator strain, spinal fluid of man & CECT \\
\hline Listeria monocytogenes CECT935 & Indicator strain, spinal fluid of child & CECT \\
\hline Listeria monocytogenes CECT936 & Indicator strain, origin not described & CECT \\
\hline Listeria monocytogenes CECT939 & Indicator strain, chicken isolate & CECT \\
\hline Listeria monocytogenes CECT4031 & Indicator strain, rabbit isolate & CECT \\
\hline Listeria monocytogenes CECT4032 & Indicator strain, soft cheese isolate & CECT \\
\hline \multicolumn{3}{|l|}{ Plasmids } \\
\hline pSIP409 & $\mathrm{Em}^{\mathrm{r}}$; pSIP401 with $256_{\text {rep }}$ and $\mathrm{P}_{\text {orf }}: \because$ gusA & {$[28]$} \\
\hline pSIP411 & $\mathrm{Em}^{\mathrm{r}}$; pSIP401 with $\mathrm{SH71}$ rep and $\mathrm{P}_{\text {orf }}$ ::gusA & {$[28]$} \\
\hline pMG36c & $\mathrm{Cm}^{r}$, pMG36e derivative & RUG-MG [30] \\
\hline pSIP409UAI & $\begin{array}{l}\text { Em }^{r} \text {; pSIP409 derivative encoding the PCR product UAI (SP }{ }_{\text {usp } 45} \text { fused to mature entA and } \\
\text { entiA genes) }\end{array}$ & This work \\
\hline pSIP411UAI & $\begin{array}{l}\text { Em }^{r} \text {; pSIP411 derivative encoding the PCR product UAI (SP }{ }_{\text {usp } 45} \text { fused to mature entA and } \\
\text { entiA genes) }\end{array}$ & This work \\
\hline pMGUAl & $\mathrm{Cm}^{r}$, pMG36c derivative encoding the $\mathrm{SP}_{\text {usp } 45}$ fused to mature ent $A$ and entiA genes) & {$[13]$} \\
\hline
\end{tabular}

a ADT, agar well diffusion test; MPA, microtitre plate asay; $\mathrm{Cm}^{\mathrm{r}}$, chloramphenicol resistance; $\mathrm{Em}^{\mathrm{r}}$, erythromycin

b CECT, Colección Española de Cultivos Tipo (Valencia, Spain); DNBTA, Departamento de Nutrición, Bromatología y Tecnología de los Alimentos, Facultad de Veterinaria, Universidad Complutense de Madrid (Madrid, Spain); RUG-MG, Department of Molecular Genetics, University of Groningen (Haren, The Netherlands) 
Biochemicals, Mannheim, Germany). E. coli XL10 Gold competent cells were transformed as described by the supplier (Stratagene). Competent L. lactis MG363 and Lactobacillus spp. cells were electrotransformed with a Gene Pulser $^{\mathrm{TM}}$ and Pulse Controller apparatus (Bio-Rad Laboratories, Hercules, CA, USA), according to Holo and Nes [47] and Aukrust and Blom [48], respectively.

\section{PCR amplification and nucleotide sequencing}

Oligonucleotide primers were obtained from SigmaGenosys Ltd. (Cambridge, UK). PCR-amplification of inserts was performed as previously described [13]. The PCR-generated fragments were purified by a NucleoSpin ${ }^{\circledR}$ Extract II Kit (Macherey-Nagel GmbH \& Co. KG, Düren, Germany) for cloning and nucleotide sequencing. Nucleotide sequencing of purified PCR products was done using the ABI PRISM ${ }^{\circledR}$ BigDye $^{\mathrm{TM}}$ Terminator cycle sequence reaction kit and the automatic DNA sequencer ABI PRISM, model 377 (Applied Biosystems, Foster City, CA, USA), at the Unidad de Genómica (Facultad de Ciencias Biológicas, Universidad Complutense de Madrid, Madrid, Spain).

\section{Recombinant plasmids derived from pSIP409, pSIP411 and pMG36c}

The primers and inserts used for the construction of the recombinant plasmids derived from pSIP409 and pSIP411 are listed in Table 4. Plasmid derivatives were constructed as follows: the primer pair USPNC-F/JJ8-R was used for PCR-amplification from total genomic DNA of L. lactis MG1363 of a 124-pb NcoI fragment (UA) encoding the $\mathrm{SP}_{\text {usp } 45}$, with a tail complementary to the DNA encoding the N-terminal sequence of EntA. Primers JJ3-F/JJ5-R were used for PCR-amplification from total genomic DNA of E. faecium T136 of a 475-bp XhoI fragment (AI) containing mature entA and entiA. Mixtures of fragments UA and AI were used as templates to amplify the 567-bp $\mathrm{NcoI} / \mathrm{XhoI}$ fragment UAI encoding the mature entA and entiA fused to the $\mathrm{SP}_{u s p 45}$. Fragment UAI was digested with the corresponding restriction enzymes and inserted into either PSIP409 and PSIP411, digested with NcoI/XhoI. The ligation mixtures were used to transform E. coli XL10 Gold and L. lactis MG1363 competent cells, respectively, and the selected plasmid derivatives pSIP409UAI and pSIP411UAI were checked by bacteriogenicity tests, PCR and sequencing of the inserts. The construction of plasmid pMGUAI has been described previously [13]. Plasmids pSIP409UAI, pSIP411UAI and pMGUAI were used to transform competent cells of $L b$. sakei Lb790, Lb. plantarum NC8 and Lb. casei CECT475.

\section{Antimicrobial activity of the recombinant Lactobacillus spp. strains}

The antimicrobial activity of colonies from the recombinant Lactobacillus spp. strains was examined by the stabon-agar test (SOAT), as previously described [49]. When appropriate, cultures were induced with $50 \mathrm{ng} \mathrm{ml}^{-1}$ of the inducing peptide SppIP [50] at an $\mathrm{OD}_{600}$ of, approximately, 0.3 and the induced cultures were grown at $30{ }^{\circ} \mathrm{C}$ for $5 \mathrm{~h}$. Cell-free culture supernatants were obtained by centrifugation of cultures at $12,000 \times g$ at $4{ }^{\circ} \mathrm{C}$ for $10 \mathrm{~min}$, adjusted to $\mathrm{pH} 6.2$ with $1 \mathrm{M} \mathrm{NaOH}$, filtered through $0.2 \mu \mathrm{m}$ pore-size filters (Whatman Int. Ltd., Maidstone, UK), and stored at $-20{ }^{\circ} \mathrm{C}$ until use. The antimicrobial activity of the supernatants was quantified by a microtiter plate assay (MPA), as previously described [13], using E. faecium P13 as the indicator microorganism. With the MPA, growth inhibition of the sensitive culture was measured spectrophotometrically at $620 \mathrm{~nm}$ with a microtitre Labsystems iEMS plate reader (Labsystems, Helsinki, Finland). One bacteriocin unit (BU) was defined as the reciprocal of the highest dilution of the bacteriocin causing $50 \%$ growth inhibition (50\% of the turbidity of the control culture without bacteriocin). The antimicrobial activity of the recombinant Lactobacillus spp. hosts was also tested against selected Listeria spp. obtained from the CECT (Colección Española de Cultivos Tipo, Valencia, Spain), using the MPA.

\section{Table 4 Primers and PCR products used in this study}

\begin{tabular}{|c|c|c|}
\hline $\begin{array}{l}\text { Primer or PCR } \\
\text { product }\end{array}$ & Nucleotide sequence $\left(5^{\prime}-3^{\prime}\right)$ or description & Amplification \\
\hline \multicolumn{3}{|l|}{ Primers } \\
\hline$J J 3-F$ & ACCACTCATAGTGGAAAATATTATGG & Al \\
\hline$J J 5-R$ & GGCGGAGCTCTCCAGGCATTAAAATTGAGATTTATCTCCATAATC & $\mathrm{Al}, \cup \mathrm{A}, \cup \mathrm{Al}$ \\
\hline USPNC-F & GAATTCTCACCATGGGAAAAAAAAAGATTATCTCAGCTATTTTAATGTCTAC & UA, UAl \\
\hline JJ8-R & CCATAATATTTTCCACTATGAGTGGTAGCGTAAACACCTGACAACGG & UA \\
\hline \multicolumn{3}{|l|}{ PCR products } \\
\hline $\mathrm{Al}$ & 475-bp Xhol fragment containing the mature enterocin A (entA) and immunity (entiA) genes & \\
\hline UA & $124-\mathrm{pb}$ Ncol fragment containing the usp45 signal peptide $\left(\mathrm{SP}_{\text {usp } 45}\right)$ and the begining of mature ent $\mathrm{A}$ & \\
\hline UAI & 567-bp Ncol/Xhol fragment containing the $\mathrm{SP}_{\text {usp } 45}$ fused to mature entA and entiA & \\
\hline
\end{tabular}




\section{ELISA for detection and quantification of EntA}

Polyclonal antibodies with predetermined specificity for EntA and a non-competitive indirect enzyme-linked inmunosorbent assay (NCI-ELISA) were used to detect and quantify EntA in supernatants of the recombinant Lactobacillus spp. strains, essentially as described [13]. Briefly, wells of flat-bottom polystyrene microtitre plates (Maxisorp, Nunc, Roskilde, Denmark) were coated overnight $\left(4{ }^{\circ} \mathrm{C}\right)$ with supernatants from $E$. faecium T136 or the recombinant strains. After addition of the anti-EntA specific antibodies and the goat anti-rabbit immunoglobulin $\mathrm{G}$ peroxidase conjugate (Cappel Laboratories, West Chester, PA, USA), bound peroxidase was determined with ABTS (2,2'-azino-bis[3-ethylbenzthiazoline-6-sulfonic acid]) (Sigma) as the substrate by measuring the absorbance of the wells at $405 \mathrm{~nm}$ with a Labsystems iEMS reader (Labsystems) with a built-in software package for data analysis.

\section{Purification of EntA and mass spectrometry analyses} EntA was purified from $L b$. sakei Lb790 (pSIP411UAI) and $L b$. casei CECT475 (pSIP411UAI), as previously described [13]. Briefly, supernatants from early stationary phase 1-L cultures of the recombinant Lactobacillus spp. strains were precipitated with ammonium sulfate, desalted by gel filtration, and subjected to cationexchange and hydrophobic-interaction chromatography, followed by reverse-phase chromatography in a fastprotein liquid chromatography system (RP-FPLC) (GE Healthcare, Barcelona, Spain). Purified fractions were subjected to matrix-assisted laser desorption/ionization time-of-flight (MALDI-TOF) mass spectrometry, as previously described [13].

\section{Authors' contributions}

JJJ carried out the cloning experiments, the immunoassays and the purification of the bacteriocin enterocin $A(E n t A)$, participated in the design of the experiments and drafted the manuscript. JB, LG and SA participated in the cloning and transforming experiments, prepared competent cells and worked in the obtention of the anti-EntA rabbit polyclonal antibodies and design of the immunoassays. DBD, IFN, CH, LMC and PEH participated in the coordination and design of the study and helped to draft the manuscript. All authors read and approved the final manuscript.

\section{Author details}

${ }^{1}$ Departamento de Nutrición, Bromatología y Tecnología de los Alimentos, Facultad de Veterinaria, Universidad Complutense de Madrid (UCM), Avenida Puerta de Hierro, s/n, 28040 Madrid, Spain. ${ }^{2}$ Department of Chemistry, Biotechnology and Food Science, Norwegian University of Life Sciences (NMBU), P.O. Box 5003, 1432 Ås, Norway.

\section{Acknowledgements}

The authors express their gratitude to Prof. L. Axelsson (NOFIMA, The Norwegian Institute of Food, Fisheries and Aquaculture Research) and Prof. J. Kok (Department of Genetics, University of Groningen, The Netherlands), for supplying plasmids pSIP409 and pSIP411, and pMG36c, respectively. This work was partially supported by Grants AGL2012-34829 from the Ministerio de Economía y Competitividad (MINECO) and AGL2009-08348 from the Ministerio de Ciencia e Innovación (MICINN), by Grant GR35-10A from the BSCH-UCM, and by Grant S2013/ABI-2747 from the Comunidad de Madrid (CAM). J. J. Jiménez was recipient of a fellowship (FPI) from the Ministerio de Ciencia e
Innovación (MICINN), J. Borrero held a research contract from the CAM, L. Gútiez held a fellowship (FPU) from the Ministerio de Educación y Ciencia (MEC), and S. Arbulu held a fellowship (FPI) from the Ministerio de Economía y Competitividad (MINECO), Spain.

\section{Competing interests}

The authors declare that they have no competing interests.

Received: 24 August 2015 Accepted: 23 September 2015

Published online: 15 October 2015

\section{References}

1. Karlskås IL, Maudal K, Axelsson L, Rud I, Eijsink VGH, Mathiesen G. Heterologous protein secretion in lactobacilli with modified pSIP vectors. PLoS One. 2014;9(Suppl 3):e91125.

2. Hazerbrouck S, Oozeer R, Adel-Patient K, Langella P, Rabot S, Wal JM, Corthier $\mathrm{G}$. Constitutive delivery of bovine $\beta$-lactoglobulin to the digestive tracts of gnotobiotic mice by engineered Lactobacillus casei. Appl Environ Microbiol. 2006;72:7460-7.

3. Sah BNP, Vasiljevic T, McKechnie S, Donkor ON. Effect of probiotics on antioxidant and antimutagenic activities of crude peptide extract from yoghourt. Food Chem. 2014;156:264-70.

4. Corr SC, Hill C, Gahan CGM. Understanding the mechanisms by which probiotics inhibit gastrointestinal pathogens. Adv Food Nutr Res. 2009;56:1-15

5. Riboulet-Bisson E, Sturme MHJ, Jeffery IB, O'Donnell MM, Neville BA, Forde BM, Claesson MJ, Harris H, Gardiner GE, Casey PG, Lawlor PG, O'Toole PW, Ross RP. Effect of Lactobacillus salivarius bacteriocin Abp1 18 on the mouse and pig intestinal microbiota. PLoS One. 2012;7(Suppl 2):e31113.

6. van Hemert S, Meijerink M, Molenaar D, Bron PA, de Vos P, Kleerebezem M, Wells JM, Marco ML. Identification of Lactobacillus plantarum genes modulating the cytokine response of human peripheral blood mononuclear cells. BMC Microbiol. 2010;10:293.

7. Corr SD, Li Y, Riedel CU, O'Toole PW, Hill C, Gahan GGM. Bacteriocin production as a mechanism for the antiinfective activity of Lactobacillus salivarius UCC118. Proc Natl Acad Sci USA. 2007;104:7617-21.

8. Dobson A, Cotter PD, Ross RP, Hill C. Bacteriocin production: a probiotic trait? Appl Environ Microbiol. 2012;78:1-6.

9. Borrero J, Jiménez JJ, Gútiez L, Herranz C, Cintas LM, Hernández PE. Use of the usp45 lactococcal secretion sequence signal sequence to drive the secretion and functional expression of enterococcal bacteriocins in Lactococcus lactis. Appl Microbiol Biotechnol. 2011;89:131-43.

10. Jiménez JJ, Borrero J, Diep DB, Gútiez L, Nes IF, Herranz C, Cintas LM, Hernández PE. Cloning, production and functional expression of the bacteriocin sakacin A (SakA) and two SakA-derived chimeras in lactic acid bacteria (LAB) and the yeasts Pichia pastoris and Kluyveromyces lactis. J Ind Microbiol Biotechnol. 2013;40:977-93.

11. Håvarstein LS, Diep DB, Nes IF. A family of bacteriocin ABC transporters carry out proteolytic processing of their substrates concomitantly with export. Mol Microbiol. 1995;16:229-40.

12. Natale $P$, Brüsser T, Driessen AJM. Sec- and Tat-mediated protein secretion across the bacterial cytoplasmic membrane: distinct translocases and mechanisms. Biochim Biophys Acta. 2008;1778:1735-56.

13. Borrero J, Jiménez JJ, Gútiez L, Herranz C, Cintas LM, Hernández PE. Protein expression vector and secretion signal peptide optimization to drive the production, secretion, and functional expression of the bacteriocin enterocin A in lactic acid bacteria. J Biotechnol. 2011;156:76-86.

14. Nes IF, Yoon SS, Diep DB. Ribosomally synthesized antimicrobial peptides (bacteriocins) in lactic acid bacteria: a review. Food Sci Biotechnol. 2007;16:675-90

15. Kjos M, Borrero J, Opsata M, Birri DJ, Holo H, Cintas LM, Snipen L, Hernández PE, Nes IF, Diep DB. Target recognition, resistance, inmunity and genome mining of class II bacteriocins from Gram-positive bacteria. Microbiology. 2011;157:3256-67.

16. Cotter PD, Ross RP, Hill C. Bacteriocins - a viable alternative to antibiotics? Nat Microbiol Rev. 2013;11:95-105. 
17. Nilsen T, Nes IF, Holo H. An exporter inducer regulates bacteriocin production in Enterococcus faecium CTC492. J Bacteriol. 2007;180:1848-54.

18. O'Keefe T, Hill C, Ross RP. Characterization and heterologous expression of the genes encoding enterocin A production, immunity and regulation in Enterococcus faecium DPC1146. Appl Environ Microbiol. 1999;65:1506-15.

19. Martín M, Gutiérrez J, Criado R, Herranz C, Cintas LM, Hernández PE. Cloning, production and expression of the bacteriocin enterocin A produced by Enterococcus faecium PLBC21 in Lactococcus lactis. Appl Microbiol Biotechnol. 2007;76:667-75.

20. Borrero J, Kunze G, Jiménez JJ, Böer E, Gútiez L, Herranz C, Cintas LM, Hernández PE. Cloning, production and functional expression of the bacteriocin enterocin A, produced by Enterococcus faecium T136, by the yeasts Pichia pastoris, Kluyveromyces lactis, Hansenula polymorpha and Arxula adeninivorans. Appl Environ Microbiol. 2012;78:5956-61.

21. Jiménez JJ, Borrero J, Gútiez L, Arbulu S, Herranz C, Cintas LM, Hernández PE. Use of synthetic genes for cloning, production and functional expression of the bacteriocins enterocin A and bacteriocin E 50-52 by Pichia pastoris and Kluyveromyces lactis. Mol Biotechnol. 2014;56:571-83.

22. Schillinger U, Lücke FK. Antibacterial activity of Lactobacillus sake isolated from meat. Appl Environ Microbiol. 1989;55:1901-6.

23. Diep DB, Straume D, Kjos M, Torres C, Nes IF. An overview of the mosaic bacteriocin pln loci from Lactobacillus plantarum. Peptides. 2009;30:1562-74.

24. Maldonado-Barragán A, Ruíz-Barba JL, Jiménez-Díaz R. Knockout of three component regulatory systems reveal that the apparently constitutive plantaricinproduction phenotype shown by Lactobacillus plantarum on solid medium is regulated via quorum sensing. Int J Food Microbiol. 2009;130:35-42.

25. Lebeer S, Vanderleyden J, De Keersmacker SCJ. Genes and molecules of lactobacilli supporting probiotic action. Microbiol Mol Biol Rev. 2008;72:728-64

26. Tsapieva A, Duplik N, Suvorov A. Structure of plantaricin locus of Lactobacillus plantarum 8P-A3. Benef Microb. 2011;2:255-61.

27. Mierau I, Kleerebezem M. 10 years of the nisin-controlled gene expression system (NICE) in Lactococcus lactis. Appl Microbiol Biotechnol. 2005;68:705-17

28. Sørvig E, Mathiesen G, Naterstad K, Eijsink VGH, Axelsson L. Highlevel, inducible gene expression in Lactobacillus sakei and Lactobacillus plantarum using versatile expression vectors. Microbiology. 2005;151:2439-49.

29. Martínez JM, Kok J, Sanders JW, Hernández PE. Heterologous co-production of enterocin A and pediocin PA-1 by Lactococcus lactis: detection by specific peptide-directed antibodies. Appl Environ Microbiol. 2000;66:3543-9.

30. van de Guchte M, van der Vossen JMBM, Kok J, Vemena G. Construction of a lactococcal expression vector: expression of hen egg white lysozyme in Lactococcus lactis subsp lactis. Appl Environ Microbiol. 1989;55:224-8.

31. Diep DB, Skaugen M, Salehian Z, Holo H, Nes IF. Common mechanisms of target cell recognition and immunity for class $\|$ bacterocins. Proc Natl Acad Sci USA. 2007;104:2384-9.

32. Gutiérrez J, Larsen R, Cintas LM, Kok J, Hernández PE. High-level heterologous production and functional expression of the sec-dependent enterocin P from Enterococcus faecium P13 in Lactococcus lactis. Appl Microbiol Biotechnol. 2006;72:41-51.

33. Mathiesen G, Sveen A, Piard JC, Axelsson L, Eijsink VGH. Heterologous protein secretion by Lactobacillus plantarum using homologous signal peptides. J Appl Microbiol. 2008;105:215-26.

34. Böhle LA, RiazT, Egge-Jacobsen W, Skaugen M, Busk ÖL, Eijsink VGH, Mathiesen $\mathrm{G}$. Identification of surface proteins in Enterococcus faecalis V583. BMC Genom. 2011;12:135.

35. Mathiesen G, Sveen A, Brurberg MB, Fedriksen L, Axelsson L, Eijsink VGH. Genome-wide analysis of signal peptide funtionality in Lactobacillus plantarum WCFS1. BMC Genom. 2009;10:425

36. Diep DB, Mathiesen G, Eijsink VGH, Nes IF. Use of lactobacilli and their pheromone-based regulatory mechanism in gene expression and drug delivery. Curr Pharm Biotechnol. 2009;10:62-73.

37. Darmon E, Noone D, Masson A, Bron S, Kuipers OP, Devine KM, van Dij $J M$. A novel class of heat and secretion stress-responsive genes is controlled by the autoregulated CssRS two-component system of Bacillus subtilis. J Bacteriol. 2002;184:5661-71.
38. Sarvas M, Harwood CR, Bron S, van Dijl JM. Post-translocational folding of secretory proteins in Gram-positive bacteria. Biochim Biophys Acta. 2004;1694:311-27.

39. Freitas DA, Leclerc S, Miyoshi A, Oliveira SC, Sommer PSM, Rodrigues L, Correa A, Gautier M, Langella P, Azevedo VA, Le Loir Y. Secretion of Streptomyces tendae antifungal protein 1 by Lactococcus lactis. Braz J Med Bio Res. 2005;38:1585-92.

40. Johnsen L, Fimland G, Eijsink V, Nissen-Meyer J. Engineering increased stability in the antimicrobial peptide pediocin PA-1. Appl Environ Microbiol. 2000;66:4798-802.

41. Böhmer N, Lutz-Whal S, Fisher L. Recombinant production of hyperthermostable CelB from Pyrococcus furiosus in Lactobacillus spp. Appl Microbiol Biotechnol. 2012;96:903-12.

42. Halbmayr E, Mathisen G, Nguyen TH, Maischberger T, Peterbauer CK, Eijsink VGH, Haltrich D. High-level expression of recombinant $\beta$-galactosidases in Lactobacillus plantarum and Lactobacillus sakei using a sakacin P-based expression system. J Agric Food Chem. 2008;56:4710-9.

43. Moraïs S, Shterzer N, Grinberg IR, Mathiesen G, Eijsink VGH, Axelsson L, Lamed R, Bayer EA, Mizrahi I. Establishment of a Lactobacillus plantarum cell consortium for cellulase-xylanase sinergystic interactions. Appl Environ Microbiol. 2013;79:5242-9.

44. Sayas-Barberá E, Viuda-Martos M, Fernández-López F, Pérez-Alvarez JA, Sendra E. Combined use of a probiotic culture and citrus fiber in a traditional sausage "Longaniza de Pascua". Food Cont. 2012;27:343-50.

45. Sidira M, Galanis A, Nikolau A, Kanellaki M. Evaluation of Lactobacillus casei ATCC 393 protective effect against spoilage of probiotic dry-fermented sausages. Food Cont. 2014;42:315-30.

46. Rojas-Ronquillo R, Cruz-Guerrero A, Flores-Nájera A, Rodríguez-Serrano G, Gómez-Ruíz L, Reyes-Grajeda JP, Jiménez-Guzmán J, García-Garibay M. Antithrombotic and angiotensin-converting enzyme inhibitory properties of peptides released from bovine casein by Lactobacillus casei Shirota. Int Dairy J. 2012;26:147-54.

47. Holo H, Nes IF. High-frequency transformation by electroporation of Lactococcus lactis subsp. cremoris grown with glycine in osmotically stabilized media. Appl Environ Microbiol. 1989;55:3119-23.

48. Aukrust T, Blom H. Transformation of Lactobacillus strains used in meat and vegetable fermentations. Food Res Int. 1992;25:253-61.

49. Cintas LM, Casaus P, Håvarstein LS, Hernández PE, Nes IF. Biochemical and genetic characterization of enterocin $\mathrm{P}$, a novel sec-dependent bacteriocin from Enterococcus faecium P13 with a broad antimicrobial spectrum. Appl Environ Microbiol. 1997;63:4321-30.

50. Eijsink VGH, Brurberg M. Hans Middelhoven P, Nes IF. Induction of bacteriocin production in Lactobacillus sake by a secreted peptide. J Bacteriol. 1996;178:2232-43.

51. Gasson MJ. Plasmid complements of Streptococcus lactis NCDO 712 and other lactic streptococcci after protoplast-induced curing. J Bacteriol. 1983;154:1-9.

52. Casaus P, Nilsen T, Cintas LM, Nes IF, Hernández PE, Holo H. Enterocin B, a new bacteriocin from Enterococcus faecium T136 which can act synergistically with enterocin A. Microbiology. 1997;143:2287-94.

\section{Submit your next manuscript to BioMed Central and take full advantage of:}

- Convenient online submission

- Thorough peer review

- No space constraints or color figure charges

- Immediate publication on acceptance

- Inclusion in PubMed, CAS, Scopus and Google Scholar

- Research which is freely available for redistribution

Submit your manuscript at

www.biomedcentral.com/submit
( Biomed Central 